\title{
УДК 550.4.02
}

\section{СИНТЕЗ НОВЫХ ПОЛИТИПНЫХ МОДИФИКАЦИЙ $\mathrm{Fe}_{7} \mathrm{C}_{3}$ ПРИ 5,5 ГПа}

\author{
А. И. Чепуров ${ }^{1, *}$, С. А. Громилов ${ }^{2,3}$, В. М. Сонин ${ }^{1}$, Е. И. Жимулев ${ }^{1}$, \\ А. С. Сухих ${ }^{2,3}$, А. А. Чепуров ${ }^{1}$, академик РАН Н. В. Соболев ${ }^{1,3}$ \\ Поступило 28.02.2019 г.
}

\begin{abstract}
В работе представлены результаты экспериментальных исследований по синтезу карбида $\mathrm{Fe}_{7} \mathrm{C}_{3}$ при 5,5 ГПа. Установлено, что вместе с алмазом при охлаждении системы образуются карбид $\mathrm{Fe}_{3} \mathrm{C}$ и несколько политипов карбида $\mathrm{Fe}_{7} \mathrm{C}_{3}$. Считается, что карбид $\mathrm{Fe}_{7} \mathrm{C}_{3}$ может быть компонентом внутреннего ядра Земли. Полученные результаты свидетельствуют, что карбид $\mathrm{Fe}_{7} \mathrm{C}_{3}$ в виде политипных модификаций в естественных условиях мог образовываться при относительно невысоких давлениях на стадии дифференциации Земли.
\end{abstract}

Ключевые слова: высокие давления, высокие температуры, алмаз, железо, карбид, политипные модификации.

DOI: https://doi.org/10.31857/S0869-56524875558-561

Система Fе-С является базовой для искусственного выращивания НРНТ-алмазов. Данная система довольно сложная вследствие образования промежуточных фаз - карбидов. Поэтому для осуществления синтеза и роста алмазов необходимо преодолеть температуры реакции образования карбидов, несмотря на относительно низкую температуру эвтектики. Обычно для подавления кристаллизации карбидов и снижения температуры плавления металла-растворителя в ростовую систему добавляют никель или кобальт. При атмосферном давлении стабильная система $\mathrm{Fe}-\mathrm{C}$ характеризуется отсутствием карбидов и наличием эвтектики графитраствор углерода в железе. В метастабильном варианте в системе имеется карбид железа $\mathrm{Fe}_{3} \mathrm{C}$, появление которого зависит от скорости охлаждения системы. Карбид $\mathrm{Fe}_{3} \mathrm{C}$ становится стабильным при 0,2 ГПа [1]. Дискуссионным в настоящее время является величина давления, при котором стабильным становится карбид $\mathrm{Fe}_{7} \mathrm{C}_{3}$.

В исследовании [2] в экспериментах до 6 ГПа карбид $\mathrm{Fe}_{7} \mathrm{C}_{3}$ в данной системе не был получен. В [3] опубликован экспериментально определённый вариант системы $\mathrm{Fe}-\mathrm{C}$ при 5,7 ГПа, в котором присутствовал карбид $\mathrm{Fe}_{3} \mathrm{C}$ и отсутствовал карбид $\mathrm{Fe}_{7} \mathrm{C}_{3}$.

\footnotetext{
1 Институт геологии и минералогии им. В.С. Соболева Сибирского отделения Российской Академии наук, Новосибирск

2 Институт неорганической химии им. А.В. Николаева Сибирского отделения Российской Академии наук, Новосибирск

3 Новосибирский национальный исследовательский государственный университет

*E-mail: chepurov@igm.nsc.ru
}

При этом авторы указанной работы установили температуру эвтектики в системе $\mathrm{Fe}-\mathrm{C} 1345^{\circ} \mathrm{C}$, а температуру реакции перитектического образования $\mathrm{Fe}_{3} \mathrm{C} 1415{ }^{\circ} \mathrm{C}$. Кристаллизация карбида $\mathrm{Fe}_{7} \mathrm{C}_{3}$ экспериментально установлена в [4] при 8 ГПа и $1400{ }^{\circ} \mathrm{C}$. При этом авторы цитируемой статьи указывают на существование эвтектики расплав $\mathrm{Fe}_{3} \mathrm{C}+\mathrm{Fe}_{7} \mathrm{C}_{3}$, которая зафиксирована также при 3,3 ГПа и $1300^{\circ} \mathrm{C}$.

После получения первых результатов в научной литературе имела место дискуссия о типе плавления карбидов железа: конгруэнтном или инконгруэнтном. При 10 ГПа фаза $\mathrm{Fe}_{7} \mathrm{C}_{3}$, несомненно, присутствует в системе $\mathrm{Fe}-\mathrm{C}$. В настоящее время принято, что оба карбида появляются путём перитектических реакций $[5,6]$. Но температура реакции образования карбида $\mathrm{Fe}_{7} \mathrm{C}_{3}$ в разных исследованиях сильно различается. Например, в работе [5] температура реакции расплав + алмаз $=\mathrm{Fe}_{7} \mathrm{C}_{3}$ при 10 ГПа составляет $2009^{\circ} \mathrm{C}$, а в [6] температура указанной реакции определена в $1650{ }^{\circ} \mathrm{C}$.

О величине давления, при котором в данной системе становится стабильным карбид $\mathrm{Fe}_{7} \mathrm{C}_{3}$, нет единой точки зрения до сих пор. Так, вслед за [4] на высокие давления появления карбида $\mathrm{Fe}_{7} \mathrm{C}_{3}$ (порядка 8 ГПа и выше) указывается в [5]. Но имеются экспериментальные исследования, в которых кристаллизация карбида $\mathrm{Fe}_{7} \mathrm{C}_{3}$ зафиксирована при 5,9 ГПа [1], 6,0 ГПа [7], 5,7 ГПа [8]. При этом в [1] указывается, что температура перитектического равновесия расплав + алмаз $=\mathrm{Fe}_{7} \mathrm{C}_{3}$ при 5,9 ГПа соответствует величине $1377^{\circ} \mathrm{C}$. А в [7] и [8] карбид $\mathrm{Fe}_{7} \mathrm{C}_{3}$ был синтезирован при 1400 и $1330{ }^{\circ} \mathrm{C}$ соответственно, т.е. параметры образования карбида $\mathrm{Fe}_{7} \mathrm{C}_{3}$ 
в этих независимых исследованиях достаточно близкие.

Кристаллизация фазы $\mathrm{Fe}_{7} \mathrm{C}_{3}$ экспериментально зафиксирована в системе $\mathrm{Fe}-\mathrm{S}-\mathrm{C}$. Cера не входит в состав карбидов, поэтому эти данные также можно учитывать. Так, по [9] карбид $\mathrm{Fe}_{7} \mathrm{C}_{3}$ зафиксирован при 6 ГПа и температуре $1300{ }^{\circ} \mathrm{C}$. По данным авторов этого исследования, увеличение количества серы в системе снижает температуру реакции расплав + + алмаз $=\mathrm{Fe}_{7} \mathrm{C}_{3}$. В исследовании [10] карбид $\mathrm{Fe}_{7} \mathrm{C}_{3}$ получен в диапазоне температур 1300-1370 ${ }^{\circ} \mathrm{C}$ при давлении 5,3-5,5 ГПа. Серосодержащие системы на основе железа являются алмазпродуцирующими при небольшом содержании серы [11].

В [12] в диапазоне давлений 7-15 ГПа была синтезирована политипная модификация $\mathrm{Fe}_{14} \mathrm{C}_{6}$, обозначенная авторами данной работы как $\left(o-\mathrm{Fe}_{7} \mathrm{C}_{3}\right)$. Цель настоящего исследования - поиск новых фаз карбида железа и их детальное исследование комплексом рентгендифракционных методов.

Эксперименты проведены на многопуансонном аппарате высокого давления “БАРС” при 5,5 ГПа и $1350{ }^{\circ} \mathrm{C}$ длительностью 1 ч. Экспериментальная методика соответствовала [10, 11]. Исходные образцы в реакционной зоне ячейки высокого давления аппарата собирали послойно: графит МГ ОСЧ находился между шайб, выточенных из электротехнической стали (углерод до 1 мас.\%, кремний 0,1 мас.\%). В другом опыте использовали прессованные таблетки из порошка железа, полученного карбонильным способом. После выдержки при температуре $1350{ }^{\circ} \mathrm{C}$ образцы без снятия давления охладили в течение 1 ч с постоянной скоростью до $1250{ }^{\circ} \mathrm{C}$, а затем закалили до комнатной темпе- ратуры в течение 5 с отключением электротока на нагревателе.

Фотографирование и химические анализы образцов после опытов производили с помощью сканирующих электронных микроскопов (SEM) MIRA LMU и JEOL JXA-8100, используя стандартные аналитические процедуры в ЦКП Многоэлементных и изотопных исследований СО РАН.

Рентгенографическое исследование поликристаллов проведено на SHIMADZU XRD-7000 (CuKo-излучение, Ni-фильтр). Идентификация синтезированных фаз проведена с использованием базы данных PDF, а также рентгеноструктурного анализа (дифрактометр Bruker APEX DUO, MoKoизлучение, графитовый монохроматор) отдельных монокристаллических осколков, отобранных из зоны, примыкающей к металлической шайбе.

Установлено, что вместе с алмазом образовался $\mathrm{Fe}_{3} \mathrm{C}$ (PDF № 01-072-1110) и несколько политипов $\mathrm{Fe}_{7} \mathrm{C}_{3}$ (рис. 1). Кристаллоструктурные характеристики одного из них соответствуют $o-\mathrm{Fe}_{7} \mathrm{C}_{3}$ [12]. Другой политип представляет собой нестехиометрическую (дефицитную по углероду) фазу $\mathrm{Fe}_{7} \mathrm{C}_{3-x}$ с удвоенным объёмом элементарной ячейки (табл. 1). Обе структуры депонированы в базе данных ICSD.

Интерес к карбиду $\mathrm{Fe}_{7} \mathrm{C}_{3}$ обусловлен также тем, что, как считается в последнее время, он может быть компонентом внутреннего ядра Земли [13]. Полученные нами результаты свидетельствуют, что карбид $\mathrm{Fe}_{7} \mathrm{C}_{3}$ в виде политипных модификаций кристаллизуется уже при 5,5 ГПа. В естественных условиях он мог образовываться при относительно невысоких давлениях на стадии дифференциации Земли при миграции расплава железа через твёрдую
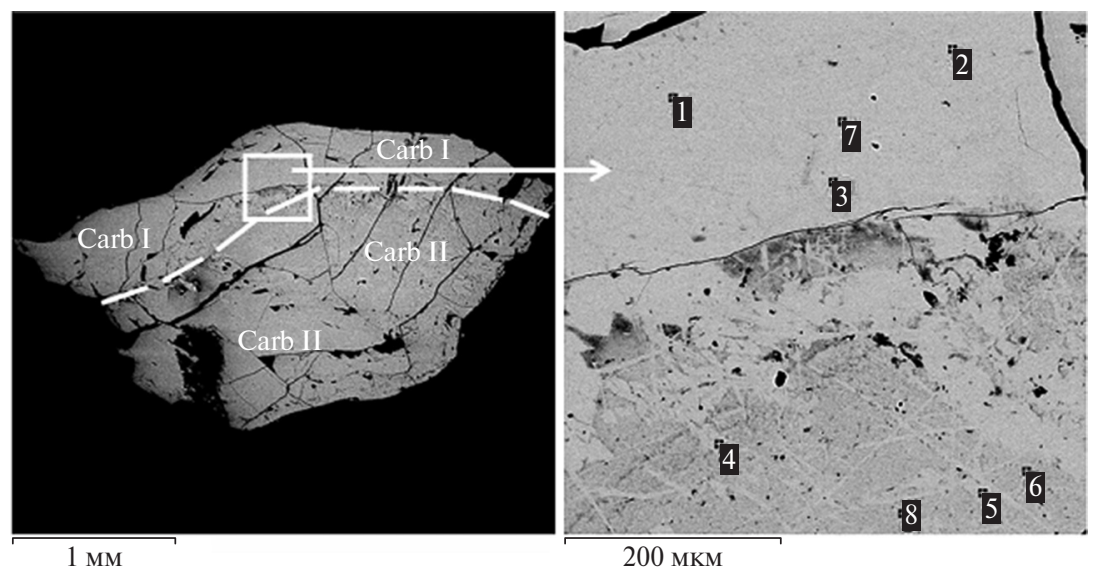

Рис. 1. SЕМ-изображения фрагмента образца с двумя зонами карбидообразования (опыт 4-5-17b). Пунктир обозначает границу между зонами с карбидом Carb I и Carb II. B зоне Carb II присутствует также Carb I в виде длинных, крупных отдельных кристаллитов. Точки на правом изображении обозначают места микроанализа образца. Содержание Fe (мас.\%) в указанных точках: $1-92,83 ; 2-92,19 ; 3-92,52 ; 4-93,59 ; 5-93,46 ; 6-93,03 ; 7-92,74 ; 8-$ 93,42 (Carb I $-\mathrm{Fe}_{7} \mathrm{C}_{3}$, Carb II $-\mathrm{FeC}_{3}$ ). 
Таблица 1. Данные рентгеноструктурного анализа

\begin{tabular}{|c|c|c|}
\hline Образец & $4-5-17 a$ & $4-5-17 b$ \\
\hline Формула & $\mathrm{Fe}_{7} \mathrm{C}_{3}$ & $\mathrm{Fe}_{7} \mathrm{C}_{3-x}$ \\
\hline Пространственная & & \\
\hline группа & $P b c a$ & $P b c a$ \\
\hline$a, \AA$ & $11,9698(6)$ & $4,5251(4)$ \\
\hline$b, \AA$ & $4,5240(2)$ & $13,7555(10)$ \\
\hline$c, \AA$ & $13,7658(6)$ & $23,9096(16)$ \\
\hline$V, \AA^{3}$ & $745,44(6)$ & $1488,3(2)$ \\
\hline$Z$ & 8 & 16 \\
\hline$\rho_{\text {calc }}, \Gamma / \mathrm{cm}^{3}$ & 7,609 & 7,623 \\
\hline$\mu, \mathrm{MM}^{-1}$ & 26,255 & 26,301 \\
\hline$F(000)$ & 1600,0 & 3200,0 \\
\hline $\begin{array}{l}\text { Число независимых } \\
\text { рефлексов }\end{array}$ & 1428 & 2272 \\
\hline $\begin{array}{l}\text { Число уточнённых } \\
\text { параметров }\end{array}$ & 92 & 209 \\
\hline$R_{\text {int }}$ & 0,0290 & 0,0597 \\
\hline$R_{\text {sigma }}$ & 0,0210 & 0,0466 \\
\hline$R_{1} / w R_{2}(I \geq 2 \sigma(\mathrm{I}))$ & $0,0245 / 0,0642$ & $0,0575 / 0,1640$ \\
\hline$R_{1} / w R_{2}$ (все рефлексы) & $0,0278 / 0,0663$ & $0,1262 / 0,2053$ \\
\hline
\end{tabular}

силикатную породу с интерстициями, заполненными графитом [14]. Твёрдый углерод в виде графита, в свою очередь, мог появиться в восстановительных условиях в результате разложения карбонатов или $\mathrm{CO}_{2}[15]$.

Источники финансирования. Работа выполнена при поддержке МИИ СО РАН № 0330-2018-0020. Химические анализы фаз в образцах выполнены по государственному заданию ИГМ СО РАН (В.М. Сонин).

\section{СПИСОК ЛИТЕРАТУРЫ}

1. Кочержинский Ю.А., Кулик О.Г., Туркевич В.З., Ивахненко С.А., Чипенко Г.В., Черепенина Е.С., Крючкова А.Р. Фазовые равновесия в системе железо-углерод при высоких давлениях // Сверхтвердые материалы. 1992. № 6. С. 3-9.

2. Верещагин Л.Ф., Штеренберг Л.Е., Слесарев В.А. О роли карбида $\mathrm{Fe}_{3} \mathrm{C}$ в синтезе алмаза // ДАН. 1970. T. 192. C. $768-770$.

3. Strong H.M., Chrenko R.M. Further Studies on Diamond Growth Rates and Physical Properties of Laboratory - Made Diamond // J. Phys. Chem. 1971. V. 75. P. $1838-1843$.

4. Zhukov A.A., Shterenberg L.E., Shalashow V.A. The Iron-Carbon System. New Developments. I. The Pseudohexagonal Iron Carbide $\mathrm{Fe}_{7} \mathrm{C}_{3}$ and the $\mathrm{Fe}_{3} \mathrm{C}-\mathrm{Fe}_{7} \mathrm{C}_{3}$ Eutectic // Acta Metallurg. 1973. V. 21. P. 195-199.
5. Lord O.T., Walter M.J., Dasgupta R., Walker D., Clark S.M. Melting in the Fe-C System to $70 \mathrm{GPa} / /$ Earth Planet. Sci. Lett. 2009. V. 284. P. 157-167.

6. Nakajima Y., Takahashi E., Suzuki T., Funakoshi K. "Carbon in the Core" Revisited // Phys. Earth Planet. Interiors. 2009. V. 174. P. 202-211.

7. Tsuzuki A., Sago S., Hirano S.-I., Naka S. High Temperature and Pressure Preparation and Properties of Iron Carbides $\mathrm{Fe}_{7} \mathrm{C}_{3}$ and $\mathrm{Fe}_{3} \mathrm{C} / /$ J. Mater. Sci. 1984. V. 19. P. 2513-2518.

8. Путятин Ф.Ф., Макарова О.В., Семененко К.Н. Взаимодействие в системе $\mathrm{Fe}-\mathrm{C}$ при высоких давлениях и температурах // Сверхтвердые материалы. 1989. № 2. C. 3-9.

9. Dasgupta R., Buono A., Whelan G., Walker D. HighPressure Melting Relations in $\mathrm{Fe}-\mathrm{C}-\mathrm{S}$ Systems: Implications for Formation, Evolution, and Structure of Metallic Cores in Planetary Bodies // Geochim. Cosmochim. Acta. 2009. V. 73. P. 6678-6691.

10. Жимулев Е.И., Сонин В.М., Миронов А.М., Чепуров А.И. Влияние содержания серы на кристаллизацию алмаза в системе $\mathrm{Fe}-\mathrm{C}-\mathrm{S}$ при 5,3-5,5 ГПа и 1300-1370 ${ }^{\circ} \mathrm{C} / /$ Геохимия. 2016. № 5. С. 439-446.

11. Жимулев Е.И., Чепуров А.И., Синякова Е.Ф., Сонин В.М., Чепуров А.А., Похиленко Н.П. Кристаллизация алмаза в системах $\mathrm{Fe}-\mathrm{Co}-\mathrm{S}-\mathrm{C}$ и $\mathrm{Fe}-\mathrm{Ni}-$ $\mathrm{S}-\mathrm{C}$ и роль металл-сульфидных расплавов в генезисе алмазов // Геохимия. 2012. № 3. С. 227-239.

12. Prescher C., Dubrovinsky L., Bykova E., Kupenko I., Glazyrin K., Kantor A., McCammon C., Mookherjee M., Nakajima Y., Miyajima N., Sinmyo R., Cerantola V., Dubrovinskaia N., Prakapenka V., Ruffer R., Chumakov A., Hanfland M. High Poisson's Ratio of Earth's Inner Core Explained by Carbon Alloying // Nature Geoscience. 2015. V. 8. № 3. 220-223.

13. Liu J., Lin J.-F., Prakapenka V.B., Prescher C., Yochino T. Phase Relations of $\mathrm{Fe}_{3} \mathrm{C}$ and $\mathrm{Fe}_{7} \mathrm{C}_{3}$ up to $185 \mathrm{GPa}$ and $5200 \mathrm{~K}$ : Implication for the Stability of Iron Carbide in the Earth's Core // Geophys. Res. Lett. 2016. V. 43. DOI: 10.1002/2016GL071353.

14. Zhimulev E.I., Chepurov A.I., Sonin V.M., Litasov K.D., Chepurov A.A. Experimental Modeling of Percolation of Molten Iron Through Polycrystalline Olivine Matrix at 2.0-5.5 GPa and $1600^{\circ} / /$ High Pressure Res. 2018. V. 38. P. 153-164.

15. Чепуров А.И., Сонин В.М., Жимулев Е.И., Чепуров А.А., Томиленко А.А. Об образовании элементного углерода при разложении $\mathrm{CaCO}_{3}$ в восстановительных условиях при высоких Р-Т-параметрах // ДАН. 2011. Т. 441. № 6. С. 806-809. 


\title{
SYNTHESIS OF NEW POLYTYPE MODIFICATIONS OF $\mathrm{Fe}_{7} \mathrm{C}_{3}$ AT 5,5 GPa
}

\section{A. I. Chepurov ${ }^{1}$, S. A. Gromilov ${ }^{2,3}$, V. M. Sonin ${ }^{1}$, A. S. Sukhikh ${ }^{2,3}$} E. I. Zhimulev ${ }^{1}$, A. A. Chepurov ${ }^{1}$, Academician of the RAS N. V. Sobolev ${ }^{1,3}$

\author{
${ }^{1}$ Sobolev Institute of Geology and Mineralogy, Siberian Branch of the Russian Academy of Sciences, \\ Novosibirsk, Russian Federation \\ ${ }^{2}$ Nikolaev Institute of Inorganic Chemistry, Siberian Branch of the Russian Academy of Sciences, \\ Novosibirsk, Russian Federation \\ ${ }^{3}$ Novosibirsk State University, Novosibirsk, Russian Federation
}

The paper presents the results of experimental studies on the synthesis of carbide $\mathrm{Fe}_{7} \mathrm{C}_{3}$ at $5,5 \mathrm{GPa}$. It was found that carbide $\mathrm{Fe}_{3} \mathrm{C}$ and several polytypes of carbide $\mathrm{Fe}_{7} \mathrm{C}_{3}$ are formed together with diamond when the system is cooled. It is believed that $\mathrm{Fe}_{7} \mathrm{C}_{3}$ carbide may be a component of the Earth's inner core. The obtained results indicate that carbide $\mathrm{Fe}_{7} \mathrm{C}_{3}$ in the form of polytypic modifications under natural conditions could be formed at relatively low pressures at the stage of differentiation of the Earth.

Keywords: high pressures, high temperatures, diamond, iron, carbide, polytype modifications. 